\title{
CRIAÇÃO E CRISTALIZAÇÃO NA DIALÉTICA DO ENSINAR E APRENDER: OS SENTIDOS QUE PROFESSORAS ATRIBUEM ÀS SUAS PRÁTICAS PEDAGÓGICAS ${ }^{+}$
}

\author{
CREATION AND CRYSTALLIZATION IN THE DIALECTIC OF TEACHING AND \\ LEARNING: THE MEANINGS THAT TEACHERS GIVE TO THEIR \\ PEDAGOGICAL PRACTICES.
}

\begin{abstract}
Maheirie K, Pereira ER. Criação e cristalização na dialética do ensinar e aprender: os sentidos que professoras atribuem às suas práticas pedagógicas. Rev Bras Crescimento Desenvolv Hum. 2006;16(1):61-67.

Resumo: Este artigo discute a partir de uma pesquisa desenvolvida com professores de $1^{\mathrm{a}}$ a $4^{\mathrm{a}}$ séries do ensino fundamental de escolas publicas, a produção de sentidos sobre a prática pedagógica que realizam, analisando o processo de criação e cristalização que constitui este fazer. A partir das contribuições do materialismo histórico-dialético e utilizando-nos da teoria sartreana como base ontológica, observamos que esse "fazer pedagógico" se faz atividade criadora não na sua integralidade, mas na dialética do processo "criação-cristalização".
\end{abstract}

Palavras-chave: Prática pedagógica. Atividade criadora. Produção de sentidos.

\section{INTRODUÇÃO}

Este artigo objetiva, a partir da pesquisa realizada para fins de mestrado, refletir sobre o processo de criação e cristalização que constitui o fazer pedagógico. A pesquisa, objetivava identificar os sentidos que professoras da escola publica atribuem às suas práticas pedagógicas.

Para definição dos termos "significados" e "sentidos", utilizamos as reflexões desenvolvidas por Vygotsky ${ }^{1}$, apropriadas para a compreensão das dimensões do coletivo e do sin- gular na mediação semiótica. Para o autor, o significado é coletivo, compartilhado, enquanto o sentido é pessoal, alterando-se em contextos diferentes. Ou seja, o sujeito produz sentidos, a partir dos significados construídos pela cultura e pelos outros que, quando apropriados se tornam instrumentos subjetivos da relação do sujeito consigo mesmo. A partir destes sentidos o sujeito se apropria, passa a "entender" o mundo, e assim definir-se no presente como o sujeito que "está sendo".

O "fazer pedagógico" tem sido discutido por Nóvoa ${ }^{2}$ Lelis $^{3}$ e Carvalho ${ }^{4}$, que defendem

\footnotetext{
+ Artigo referente à dissertação de mestrado de título Criação e cristalização na dialética do ensinar e aprender: um estudo em torno dos sentidos que professoras atribuem as suas práticas pedagógicas, apresentada no Programa de Pós-Graduação em Psicologia da UFSC, sob orientação da Prof. Dra. Kátia Maheirie.

* Doutora em Psicologia Social pela PUC/SP e professora do Departamento e do Programa de Pós Graduação em Psicologia da Universidade Federal de Santa Catarina (UFSC).

** Mestre em Psicologia pela UFSC, professora do curso de Psicologia da FACVEST. e-mail: e.pereira@ estadao.com.br Rua Henrique Borba Santos, 110. Apto 33/ B1 05 Cordeiros Itajai/SC 88310.300
} 
uma formação alicerçada em práticas coletivas e reflexivas, acreditando que esta contribui para a emancipação do fazer docente. Eles discutem que os obstáculos desse processo serão superados com uma formação adequada que permita ao professor assumir as responsabilidades de sua prática. Por sua vez, Basso ${ }^{5}$ discute numa perspectiva histórico-dialética a autonomia da prática docente, fundamentada na particularidade do processo, estabelecendo uma relação direta entre formação (básica e continuada) e prática. Para o autor, analisar o trabalho docente, é entender a relação entre as condições subjetivas - formação do professor - e as condições objetivas - desde a organização da prática em si até a remuneração do professor. $\mathrm{O}$ autor discute ainda que a alienação do trabalho docente é gerada pela ruptura entre significado - finalidade do trabalho definida socialmente e sentido - definido pelo próprio professor.

Com base nestas leituras, percebemos que a afetividade tinha papel coadjuvante neste fazer, assim, buscamos auxilio de Sawaia ${ }^{6}$ e Sartre $^{7}$ para entender que a afetividade atravessa todo fazer reflexivo, num movimento dialético de construção e desconstrução do fazerse professor. "A afetividade, em síntese, envolve todas as relações humanas consideradas espontâneas, seja percepção, imaginação ou reflexão, contemplando, assim, os sentimentos e as emoções como forma específica de relação entre subjetividade e objetividade". ${ }^{8}$ (p.148). A afetividade altera o modo como o sujeito significa o mundo tanto positivamente quanto negativamente.

A partir destas reflexões, encontramos em autores como Vasconcelos ${ }^{9}$, Mignot e Cunha ${ }^{10}$, e Fontana ${ }^{11,12}$, a importância de dar "voz" as professoras, os sujeitos desse processo.

Buscamos então, com o auxilio de Zane$11 \mathrm{a}^{13}$ compreender o "fazer pedagógico" como processo em construção, como um fazer mediado pelo outro. Para tanto, nos instrumentalizamos em Vygotsky ${ }^{14}$, Zanella, Balbinot e Perei$\mathrm{ra}^{15}$ e Maheirie ${ }^{8}$ que discutem a questão da atividade criadora como possibilidade do sujeito reorganizar seu cotidiano, transformando-o. Ainda com Sartre ${ }^{16}$, apontamos a importância do projeto como determinante do "ser quem se é" e de mover-se em qualquer objetivação na vida.

\section{MÉTODO}

Os sujeitos da pesquisa são professores das escolas públicas municipais, estabelecidas em Penha, Santa Catarina. No momento da coleta de dados o município contava com 37 professores distribuídos em 17 unidades escolares, sendo que 20 deles se dispuseram a participar.

A coleta dos dados baseou-se inicialmente em um questionário ${ }^{* * *}$ que se propôs a investigar os aspectos socioeconômicos do grupo de professores e da população por eles atendida; as possíveis interferências frente à avaliação dos alunos, sua formação profissional, jornada de trabalho, tempo de serviço, lazer, escolha profissional e prática pedagógica. Com base nas respostas destes professores, selecionamos as professoras Léia, Rita, Nelci, Irene e Inês ${ }^{\#}$ para esta pesquisa. As entrevistas foram gravadas em

\footnotetext{
*** Os nomes dados aos entrevistados são fictícios.

\# O questionário utilizado nesta pesquisa faz parte de um projeto intitulado "Constituição do sujeito e atividade criadora: investigando professores das séries iniciais do ensino fundamental em contextos de formação continuada". Trata-se de um projeto de pesquisa integrado, o qual congrega educadores e psicólogas, de instituições de ensino superior, a saber, UFSC, UNIVALI e FURG, financiado pelo CNPq. Tal investigação é embasada na perspectiva da psicologia histórico-cultural, e tem como coordenadora a profa. Dra. Andréa Vieira Zanella. Com base nesse questionário, acrescentamos três questões discursivas sobre a escolha e prática profissional dos professores com o objetivo de permitir-lhes maior liberdade na maneira de pensar, favorecendo assim um resgate de suas memórias afetivas.
} 
fita cassete visando à fidedignidade na coleta e transcrição dos dados.

A análise dos dados priorizou a articulação entre os sentidos e significados contidos nas falas dos professores entrevistados, sendo deste modo, uma análise de conteúdo. Para Franco ${ }^{17}$, a "análise de conteúdo é uma técnica de pesquisa cujo objetivo é a busca do sentido ou dos sentidos de um texto" (p.165). Ruiz-Olabuéna$\mathrm{ga}^{18}$ corrobora com este pensamento quando diz que análise de conteúdo é uma técnica para ler e interpretar o conteúdo de qualquer tipo de documentos.

Seguindo as orientações de Ruiz-Olabuénaga ${ }^{18} \mathrm{e} \mathrm{Franco}^{17}$, buscamos após a transcrição das fitas, separar as falas, conteúdos e emoções em categorias de análise e em seguida, reintegrá-los para compreendê-los numa totalização. As categorias foram escolhidas a posteriori, por entender que elas deverão ser “ (...) criadas, à medida que surgem nas respostas, para depois ser interpretada à luz das teorias explicativas"17. (p.176).

A análise se constituiu num movimento que pretendeu ir da situação singular para a situação coletiva em que o sujeito está inserido, buscando entender suas ideologias, produção de valores, suas aspirações, necessidades, possibilidades e impossibilidades concretas.

\section{RESULTADOS E DISCUSSÃO}

Nossa analise permitiu identificar diferentes momentos de cristalização e de apatia em relação à prática pedagógica, que se completam e se alternam com momentos de criação e transcendência daquilo que vivenciam nesta prática.

Um dos aspectos da pesquisa que nos faz refletir é o sentido atribuído pelas professoras à relação que estabelecem com seus alunos. Algumas estabelecem relações de troca, que determinam a cada um deles um lugar soci- al que só existe e se define a partir da existência do outro. Esta significação permite ao professor organizar um planejamento que prioriza as vivências dos alunos. Esta postura transforma o cotidiano em currículo, ampliando as possibilidades para que o sujeito se aproprie, a seu modo, de sua vida e passe a se tornar um condutor de sua história.

"eles são seres incríveis, eles são umas feras. Em tudo, (...). Eles são a paixão da minha vida, (...) pra mim eles são únicos, importantes e faço eles se sentirem assim”. (Léia)

Segundo Zanella e Da Ros ${ }^{19}$, quando o professor reconhecer no aluno um parceiro que deve ser respeitado no processo de ensinar e aprender, baseará seu fazer num "currículo" que transcende a "formatação original" e, assim, será capaz de fazer-se novo.

"mas ela se torna produtiva a partir do momento em que aquilo que eles tão aprendendo faça sentido pra vida deles".(Léia)

Aqui, Léia realiza o processo que é descrito por Sartre ${ }^{20}$ como compreensão: “compreendemos seu ato pela situação, a situação por seu ato e, ambos, a um só tempo, acabam por nos fornecer uma compreensão acerca do que ele quer e do que ele sente". (p.73), e assim apreende o processo de ensinar e aprender vivido pelas crianças a partir do sentido que elas dão a suas vidas. Enquanto professor, ela se apropria da ação do outro e por isso o compreende.

Diferentemente, a professora Nelci aponta uma não compreensão da condição de troca ou parceria realizada entre professor e aluno. A não compreensão desta condição se faz cristalizadora da prática, acarretando na exigência de que o aluno, parceiro deste fazer, abra mão de sua singularidade, sua história, seu contexto em função unicamente do projeto do professor. Assim, o ensinar tem como base a história do professor e não o cotidiano das crianças. 
"eles são fracos. Eu consigo trabalhar bem com eles, mas eles precisam muito de mim. Mas de aprendizagem é uma turminha lenta, mas é boa (...) Eu parto do meu ponto de vista, vendo o mais certo ou o mais fácil pra eles, com base naquilo que eu entendo, aquilo que eu vejo". (Nelci)

Outro sentido atribuído à prática pedagógica, destacado neste artigo, refere-se às dificuldades vividas nesse fazer-se professor. As professoras destacam a precariedade das condições do ambiente em que trabalham e as críticas vazias, realizadas por aqueles que "olham de fora" o fazer do professor.

"tu fazer algum sucesso depende só de ti. Observa só o ambiente, salas de aula, carteira, cadeira, quadro e giz, poucos livros (...)”. (Léia)

Léia assume a condição social em que está inserida e a partir desse reconhecimento busca transcendê-las e "fazer sucesso", parecendo concordar com Sartre ${ }^{16}$, quando este escreve que o homem faz sua história, mas "se a História me escapa, isto não decorre do fato de que não a faço: decorre do fato de que o outro também a faz". (p.150). Assim, o contexto pode apresentar limites concretos, mas, apesar destas situações, são os homens que fazem sua história. A análise permite apontar ainda a questão salarial que se mostra, em muitos momentos, como finalizador de projetos e, assim, causador de desprazer. A questão salarial é discutida por Fontana ${ }^{11}$, vista como mercantilização do fazer-se professor, entendendo o salário enquanto finalizador de projetos pessoais.

"e u não conto muito com o salário (...) porque, quando eu escolhi essa profissão, eu sabia que o salário era esse (...) lógico que a gente tinha que ganhar mais, mas isso é um trabalho do coletivo, e se a gente não se organizar não vai ter (...) nós precisamos nos unir (...)”. (Rita)

Por mais que a professora afirme aceitar o salário que recebe e acredite na força da cole- tividade, o faz como forma de apagar o desprestígio vivido na singularidade e originado pelo baixo salário, como pode ser visto na continuação de sua fala.

"A nossa aparência também conta, nós temos que nos vestir de modo que passe credibilidade e como com um salário desses. Aí eles vêem um professor mal vestido e doente (...)”. (Rita)

A questão salarial é vivida por Rita na contradição, pois ora o baixo salário é justificado pela escolha profissional realizada, ora é vivido como impossibilidade, como sendo causador de desprazer, dificultando a superação de sua condição social. A credibilidade não está na roupa em que veste, mas estar bem vestida permite que ela dê conta do papel social que assumiu, vivenciando a mediação estética no seu fazer profissional.

Um outro aspecto pertinente, que pôde ser identificado na objetivação das professoras, está relacionado à superação e conservação vivida no movimento de constituir-se professor. As entrevistas nos permitem refletir que a inexperiência exige do professor uma posição que revele que ele domina "todo" o conteúdo e, assim, verticaliza o processo, dirigindo-se ao aluno como "dono do saber". Porém, quando dominam a atividade, desenvolvem estratégias para saírem da mesmice e se constituem professores experientes. Professores capazes de estabelecer uma relação de parceria, onde ensinam e aprendem simultaneamente, capazes de identificar novos signos para avaliarem constantemente sua prática.

“(...) o primeiro ano que eu peguei a primeira série, eu cheguei muitas vezes em casa com dor de cabeça de preocupação (...) primeira série requer muito da gente, requer esforço, dedicação, o dom pra gente entrar em sala de aula e ensiná-los (...). O meu medo era esse, como é que eu ia conseguir abriro entendimento dela com a leitura?" (Inês).

O sofrimento da iniciação é amenizado 
pela experiência, pelas vivências positivamente significadas e pela mediação dos outros em seu fazer.

"No primeiro ano (...), eu me via perdida, eu nem sabia como começar, mas tive muita ajuda aqui nessa escola pelo especialista e a diretora. Me ajudaram muito dizendo como fazer, e hoje eu já entro em sala de aula sabendo como começar, (...)Antes eu me perdia nessa parte de trabalhar com texto. Como eu ia trabalhar um texto se eles não sabiam ler, agora eu consigo". (Inês).

As professoras descrevem os momentos em que transcendem ao tradicional e os momentos em que os conservam, falam da semana de provas, que é mantida para dar conta da pressão dos pais e da direção da escola à avaliação dos alunos, mas relatam não utilizar questionários nas provas, buscando questionamentos que permitam ao aluno apresentar uma reflexão sobre o tema.

Rita revela que transcende a alfabetização quando descobre que existem novas ordens alfabéticas, e solicita a participação dos alunos para construção dessa nova ordem.

"Eu não ensino as crianças na ordem das letrinhas, eu convido as crianças a escolherem as letras e fazer uma nova ordem, (...). Quando eles escolhem as letras, eles ficam entusiasmados". (Rita)

A busca pela superação exige destas professoras um resgate das experiências vividas por seus alunos assim como a desconstrução e a reconstrução dessas experiências, possibilitando a apropriação de novos significados. A simples "troca" na forma como escolhe o conteúdo a ser trabalhado é a recombinação do rotineiro transformando-o em processo criativo. Deste modo, re-significa a atividade, compreendendo que existem novas ordens alfabéticas e não apenas aquela determinada por uma regra. Ela aproxima a atividade ao cotidiano da criança e possibilita que elas re-signifiquem a ação e, assim, transcende a alfabetização que se constrói conhecimento pela ação criadora.

Os resultados da pesquisa nos fazem refletir que a prática pedagógica não se faz de forma linear, mas dialética, sendo síntese inacabada, sendo movimento de totalizações, que se objetiva na contradição do ora crio, ora cristalizo. As entrevistas revelaram tais contradições, e elas mesmas apontaram possibilidades, quando destacaram a importância da mediação dos professores com os quais dividem o espaço escolar, e de suas próprias vivencias, aprendendo a resolver problemas ou na definição de quais caminhos consideram não dever seguir.

$\mathrm{Na}$ coletividade, essas professoras se reconhecem e se constituem enquanto tal. Portanto, se o trabalho coletivo as constitui, faz-se necessário a organização de "momentos de práxis", onde as professores possam, articulando presente-passado-futuro, refletir sobre sua atividade, sua história. Partindo do entendimento que falar produz significados, por meio da troca de experiências, faz-se possível re-significar a atividade transcendendo o contexto.

"eu sempre gosto de pegar as idéias dos meus amigos porque eu aprendo muito com outros professores Eu sempre tô conversando com um amigo sobre como posso fazer isso (...)Eu acho que deveria ter um espaço para que o professor pudesse trocar idéias aqui na escola”.(Inês)

Elas revelam o desejo por um espaço onde possam realizar essas trocas, onde possam refletir sobre seu fazer, buscando uma ação coletiva, com possibilidades de fugirem da repetição, da indiferença, singularizando e superando o fazer. Andaló ${ }^{21}$ sugere um processo de "formação em serviço", onde os professores pudessem repensar suas práticas. Um lugar onde pudessem resgatar o sentido do "nós", onde "passariam a questionar seu próprio conhecimento, conscientizando-se da necessidade de buscar alternativas de ação (...). E, nesse sentido, o compromisso político é que levaria à competência técnica e não o inverso". (p.196). 
Faz-se necessário, portanto, que no coletivo essas professoras re-signifiquem a ação como devendo ser modificada, superando as condições impostas pelo contexto e criando. É importante que juntas percam o medo por inovar, por modificar e assumam-se responsáveis pelo ensinar e aprender.

\section{CONCLUSÃO}

As entrevistas revelaram semelhanças desde a compreensão que tinham sobre suas escolhas até o desejo de superarem a posição de professor "dono do saber", assumindo uma postura de parceira, entendendo o ensinar e aprender como processo que se complementa. Isto indica o pertencimento a um lugar histórico comum e a busca por uma postura que não se permite cristalizar, superando dialeticamente a posição assumida inicialmente.

Elas apontaram ainda o "caráter mágico" do fazer docente, destacado no momento do aprender da criança como um motivo de seu encantamento. Esta sensação de "magia" envolvendo seu trabalho indica que sua atividade é permeada pela afetividade. Produto de uma relação emocional, tanto professor quanto aluno se encontram mergulhados na emoção tal como Sartre ${ }^{7}$ aponta, quando escreve que estar emocionado significa "constituir um mundo mágico, utilizando o nosso corpo como meio de encantamento" (p.65). Nesse mundo mágico, o ensinar e o aprender se unem "numa síntese indissolúvel" (p.49).

As entrevistas mostraram que a autonomia não está na formação docente, mas na compreensão afetivo-reflexiva que aponta para o seu fazer como um fazer-se constante ${ }^{5}$. As entre- vistas revelaram ainda que a busca pela qualificação amplia as possibilidades de novos projetos, apresentando-se como "potência de ação"\#\#, qual seja, como força para transcender as impossibilidades do contexto.

Reconhecendo que um ponto final não dá conta da totalidade de um processo, retornamos ao referido na introdução, qual seja, a importância de dar "voz" aos professores, sujeitos do processo. Com base em Vasconcelos $^{9}$, Mignot e Cunha ${ }^{10}$ e Fontana ${ }^{11,12}$, buscamos resgatar suas trajetórias, possibilidades e impossibilidades concretas e, assim, revelar suas verdades. Porém, uma vez que coexistem verdades, apresentamos algumas delas a partir das entrevistas, existindo outras que também devam ser ditas. Sugerimos, deste modo, o aprofundamento do fazer pedagógico mediado pela afetividade, ou ainda, visando novas descobertas, desenvolver uma melhor compreensão da relação entre formação docente e atividade criadora a partir do conceito de "potência de ação".

$\mathrm{Na}$ cristalização, o fazer do professor se objetiva na repetição do ensinar a ler e escrever, enquanto na criação, como dizem Mignot e Cunha ${ }^{10}$, o fazer do professor é produtor de sonhos, dificuldades, singularidades e situações espetaculares. Adiferença está no momento em que o professor se escolhe como sujeito responsável pelo processo, ampliando suas possibilidades de constituir sua atividade em "atividade criadora", na medida em que articula o pensar, o agir e o sentir nesta direção. $\mathrm{Na}$ medida em que sente a necessidade de assim fazê-la para si e para o outro, é capaz de reconhecer a si e aos seus alunos como diferentes, ampliando seu universo de possibilidades em direção a novos objetivos.

\footnotetext{
\#\# Para Sawaia ${ }^{22}$, baseada em Spinoza, "potência de ação" é "o momento da transformação das relações objetivas que aprisionam as emoções, a aprendizagem, a humanidade e a sensação de impotência se transforma em energia e força para lutar" (p.159). Assim, por potência de ação entendemos força individual que permite ao sujeito transcender as condições de existência, é promovida por uma reflexão afetiva mediadora dos acontecimentos objetivos.
} 


\begin{abstract}
This article discusses how teachers give meaning to their pedagogical activities. The discussion is based on a research study developed with teachers of grades 1 to 4 of public elementary schools and also on an analysis of the process of creation and crystallization that constitutes this pedagogic activity. Based on the contributions of the dialectical historical materialism and making use of Sartre's theory as an ontological basis, it is observed that this "pedagogic activity" becomes "creative activity" not in its own integrity, but in the dialectic of the "creation-crystallization" process.
\end{abstract}

Key words: Pedagogic activity. Creation activity. Production of meanings.

\section{REFERÊNCIAS}

1. Vygotsky LS. Obras escogidas II. Madrid: Visor Distribuciones; 1992. Pensamiento y palabra. p. 287-348.

2. Nóvoa A, coordenador. Os professores e a sua formação. Lisboa: Dom Quixote; 1995.

3. Lelis IA. A formação da professora primária: da denúncia ao anúncio. São Paulo: Cortez/ Autores Associados; 1989.

4. Carvalho M. Formação de professores e trabalho docente. In: Ferro MAB, organizador. Educação: saberes e práticas. Teresina: EDUFPI; 2002.

5. Basso IS. Significado e sentido do trabalho docente. Cad CEDES. 1998;19(44):19-32.

6. Sawaia BB. Comunidade como ética e estética de existência: uma reflexão mediada pelo conceito de identidade. Psyche (São Paulo). 1999;8(1):19-25.

7. Sartre JP. Esboço de uma teoria das emoções. Rio de Janeiro: Zahar; 1965.

8. Maheirie K. Processo de criação no fazer musical: uma objetivação da subjetividade, a partir dos trabalhos de Sartre e Vygotsky. Psicol Estud. 2003;8(2):147-53.

9. Vasconcelos GAN, organizador. Como me fiz professora. Rio de Janeiro: DP\&A; 2003.

10. Mignot ACV, Cunha MTS. Práticas de memórias docente. São Paulo: Cortez; 2003.

11. Fontana RC. A constituição social da subjetividade: notas sobre Central do Brasil. Educ Soc. 2000;21(71):221-34.

12. Fontana RC. Trabalho e subjetividade: nos rituais da iniciação a constituição do ser professora. Cad CEDES. 2000;20(50):103-19.

13. Zanella AV. Relações sociais em sala de aula: reflexões à luz da psicologia histórico-cultural. In: Anais do III Congresso Nacional de Reorientação Curricular; 2002 jul 05-07; Blumenau, Brasil. Blumenau (SC): Prefeitura Municipal/Edifurb; 2002. p. 47-50.

14. Vygostsky LS. La imaginación y el arte en la infancia. Madrid: Akai; 1990.

15. Zanella AV, Balbinot G, Pereira RS. Re-criar a (na) renda de bilro: analisando a nova trama tecida. Psicol Reflex Crit. 2000;13(3):539-47.

16. Sartre JP. Questão de método. São Paulo: Abril Cultural; 1978.

17. Franco MLPB. Ensino médio: desafios e reflexões. Campinas: Papirus; 1994.

18. Ruiz-Olabuénaga JI. Metodología de la investigación cualitativa. Bilbao: Universidad de Deusto; 1999.

19. Zanella AV, Ros SZ. O lugar social do professor em sala de aula: questões a considerar em sua formação. In: Anais do IV Seminário de Pesquisa em Educação da Região Sul (ANPED) [CD-ROM]; 2002 nov 26-29; Florianópolis, Brasil. Florianópolis(SC): UFSC/NUP; 2002.

20. Sartre JP. Sartre no Brasil: a conferência de Araraquara. Rio de Janeiro: Paz e Terra; São Paulo: UNESP; 1960.

21. Andaló CSA. Fala, professora!: repensando o aperfeiçoamento docente. Petrópolis: Vozes; 1995.

22. Sawaia BB. Dimensão ético-afetiva do adoecer da classe trabalhadora. In: Lane STM, Sawaia $\mathrm{BB}$, organizadores. Novas veredas da psicologia social. São Paulo: Brasiliense/EDUC; 1995.

Recebido em 31/10/05

Modificado em 29/11/2005

Aprovado em 07/12/2005 